\title{
Preface of the "Symposium on Numerical Optimization and Applications"
}

\author{
Ana I. Pereira and M. Fernanda Costa \\ ${ }^{a}$ Instituto Politécnico de Braganca, Escola Superior de Tecnologia e Gestão, \\ Gabinete 54, 5301-857 Bragança-Portugal \\ ${ }^{b}$ Department of Mathematics and Applications, University of Minho, \\ Campus de Azurém, 4800-058 Guimarães, Portugal
}

Numerical Optimization and Applications Symposium emphasizes modeling, theory and study of numerical algorithms for optimization. Optimization is an important tool in decision science and in the analysis of physical systems. Furthermore the Optimization plays central role in a tremendous variety of application in the natural sciences, in the sectors of economy, finance, and industry operational research and in the engineering. Because of the wide and growing use of optimization, it is important to develop an understanding of optimization algorithms. Knowledge of the capabilities and limitations of these algorithms leads to a better understanding of their impact on various applications, and points the way to future research on improving and extending optimization algorithms and software.

Our goal in this session is to illustrate some modern optimization techniques in our days, by presenting efficient methods to solve different type of optimization problems including some real world problems.

\section{Ana Isabel Pinheiro Nunes Pereira}

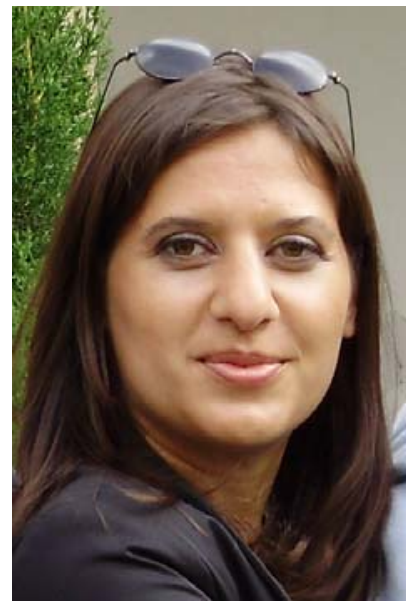

Ana Isabel Pinheiro Nunes Pereira, Assistant Professor at the Department of Mathematics, Polytechnic Institute of Bragança, and she is a member of the Algorithm Research Centre - Minho University. She got her PhD at Minho University (2006) in 'Numerical Optimization' area with the thesis "A reduction method to solve semiinfinite programming problems". She is author or co-author of more than thirty journal papers, book chapters and conference proceedings.

Email: apereira@ipb.pt

ORCID: http://orcid.org/0000-0003-3803-2043

ResearchID: F-3168-2010

ResearchGate: https://www.researchgate.net/profile/Ana_Pereira26

\section{Maria Fernanda Pires da Costa}

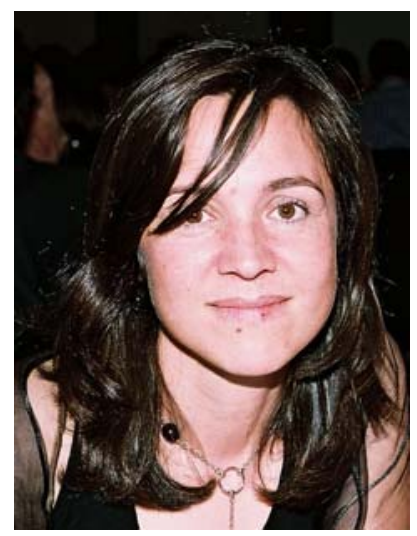

M. Fernanda P. Costa is Assistant Professor of the Department of Mathematics and Applications, and is member of the Centre of Mathematics, at University of Minho (Portugal). She got her $\mathrm{PhD}$ at University of Minho in Mathematics in 2002. Her research interests is in nonlinear optimization. She is author or co-author of more than thirty journal papers and conference proceedings.

Email: mfc@math.uminho.pt

ORCID: http://orcid.org/0000-0001-6235-286X 